\title{
Os Impactos Econômicos da Atuação do Sistema Penal: vida virtual, isolamento e encarceramento em massa ${ }^{1}$
}

\section{The Economic Impacts of the Penal System Performance: virtual life, isolation and mass incarceration}

\author{
Sergio Francisco Carlos Graziano Sobrinho \\ Pontifícia Universidade Católica do Rio Grande do Sul - Porto Alegre, RS, Brasil
}

\begin{abstract}
Resumo: Este artigo objetiva compreender a atuação do sistema penal brasileiro a partir dos índices de encarceramento dos últimos 20 anos, interagindo o conceito econômico da maximização dos lucros com o discurso criminológico da seletividade do sistema penal. As transformações discursivas no campo das políticas criminais, caracterizadas por uma constante e forte repressão penal, passando do "previdenciarismo penal" (correção) ao aumento das punições, sofrem importante interferência do modelo econômico, em especial modulando as práticas de encarceramento com interesses privados e produzindo significativo aumento dos índices de encarceramento, permanente seletividade da atuação do sistema penal e transformações, tanto no modo de vida contemporâneo como na atuação e nas estruturas dos órgãos de controle e de justiça criminais.
\end{abstract}

Palavras-chave: Encarceramento. Privatização. Seletividade.

1 Recebido em: 14/7/2014

Revisado em: 8/10/2014

Aprovado em: 14/10/2014

\begin{abstract}
This article aims to understand the role of the criminal justice system from the incarceration rates of the past 20 years, interacting economic concept of profit maximization with the criminological discourse of selectivity of the penal system. The discourse transformations in the field of criminal policy, characterized by a constant and strong prosecution, passing "penal welfarism" (correction) the increase in punishment, suffer significant interference from the economic model, in particular modulating the practices of incarceration with private interests, producing a significant increase in incarceration rates, permanent selectivity of action of the penal system and the changes in both the contemporary way of life as the action of the organs and structures of control and criminal justice.
\end{abstract}

Keywords: Incarceration. Privatization. Selectivity. 


\section{Introdução}

O cenário de violência que se estabeleceu nas últimas décadas nos ambientes urbanos brasileiros favoreceu a realização de pesquisas com coleta de dados suficientes para permitir e entender esse fenômeno e avançar em algumas conclusões sobre os caminhos a serem trilhados no enfrentamento do problema. Contudo, a partir da necessária compreensão da atuação do sistema penal brasileiro, mormente pelos déficits existentes no modelo tradicional de resposta à criminalidade, baseado principalmente na atuação seletiva das polícias e no encarceramento em massa, o problema da capacidade do sistema penal em responder as demandas sociais torna-se um dos mais importantes objetos da sociologia da administração da justiça, justamente em razão das expectativas dos cidadãos na atuação das instituições públicas.

A pretensão do presente ensaio é entender o significado, as consequências e as motivações econômicas do aumento dos índices de encarceramento, justamente em razão das profundas alterações discursivas no campo das políticas criminais, as quais passaram do modelo previdenciárismo penal (correção) ao aumento das punições e sofrem importante interferência do modelo econômico, modulando as práticas de encarceramento com interesses privados.

A constatação mais evidente do aumento do encarceramento no Brasil pode ser vista no significativo aumento da população carcerária nos últimos 20 anos. Para se ter ideia desse crescimento, em 1995 havia pouco mais de 148 mil pessoas submetidas ao regime de encarceramento, hoje são 567.655 presos, mais 147.937 pessoas em prisão domiciliar, totalizando 715.655 pessoas presas. É preciso computar - para uma análise do universo que se está trabalhando - conforme dados do DEPEN do ano de 2009, mais 671.078 pessoas submetidas a algum tipo de controle penal extramuros, como as penas alternativas (126.273 pessoas) criadas pela Lei n. 9.714/1998, e medidas alternativas (544.795 pessoas) previstas na Lei n. 9.099/1995, como a transação penal, suspensão condicional do processo e a composição civil. Apesar dos dados não estarem atualizados em relação às penas e às medidas alternativas, é possível dizer que hoje no Brasil há mais de 1.386.733 pessoas submetidas à ação direta do sistema penal. 
Nesse sentido, com a finalidade de verificar os impactos econômicos da atuação do sistema penal, será analisado em um primeiro momento, quantitativamente, o crescimento da população submetida ao sistema penal brasileiro, estabelecendo, em seguida, as conexões necessárias entre o ideal de recuperação do condenado, a prática discursiva e as alterações das condições socioeconômicas brasileiras nos últimos anos, isso porque, ainda que essas condições tenham melhorado, os índices de encarceramento continuam aumentando.

Destaque-se, como objetivo principal do presente trabalho, que a análise dos impactos econômicos decorrentes da atuação do sistema penal segue a lógica do mercado, isto é, da reprodução do capital. Há, na verdade, uma "modelação" do sistema penal ao sistema econômico, o que lhe permite realizar o capital por meio de uma dinâmica própria. Essas conexões são geradas pela comunicação de diversas variáveis, em especial pela necessidade da reprodução do capital pela busca de lugares próprios à sua reprodução. Interessante observar como o próprio sistema faz sua autorregulação, justamente em razão da dificuldade de se encontrar espaços à reprodução do capital o sistema econômico encontrou no sistema penal o local apropriado a essa finalidade. Foi necessário adequar a categoria sociológica da "violência" à categoria econômica, caracterizando-a como produto de consumo. Esse foi o passo decisivo para modular o sistema penal às características da sociedade de consumo, isso porque foi necessário aumentar o consumo do "produto segurança" e permitir a continuidade das relações comerciais tradicionais. O resultado dessa simbiose foi avassalador, pois os vetores apontaram para a banalização da violência, permitindo que ela se tornasse um desejado objeto de consumo, surgindo uma enorme quantidade de produtos. Analisando de outra forma, as consequências dessa nova realidade não são menos assustadoras, pois os espaços para a reprodução do capital foram encontrados nas relações virtuais, o que está produzindo, em certa medida, o isolamento e a guetificação das pessoas e dos sujeitos que não reconhecem a existência do outro, justamente em função da virtualidade dos relacionamentos. 


\section{O Encarceramento em Massa e as Mudanças das Políticas Penais}

A partir das alterações que passaram a ocorrer na Europa entre a segunda metade do século XVI ${ }^{2}$ e o final do século XVIII, com o triunfo do capitalismo, as estratégias de poder mudaram, como afirma Foucault, do regime de poder soberano, de uma função de destruição física dos criminosos, ao regime de disciplinamento dos corpos, quando se inicia o chamado período dos "grandes internamentos".

O objetivo principal do encarceramento era de constituir uma massa de trabalhadores dóceis e úteis, a fim de transformar sujeitos camponeses em "força de trabalho livre". Esta complexa relação produziu um enorme poder e disponibilidade sobre a força produtiva, tornando-a cada vez mais apta (e domesticada) à expansão do capitalismo.

Esta relação entre discursos econômicos e jurídicos penais, especificamente com a possibilidade da expansão da atuação do sistema penal, inclusive com legislações mais rígidas e encarceramento em massa, permite, em certa medida, o aprofundamento da intervenção penal na vida social em locais que antes não havia a regulação do sistema penal. Esta reflexão inicial permite identificar a intervenção pública do sistema penal para dirimir conflitos sociais, transfigurando-o como principal instrumento público de gestão e não mais na proteção dos direitos e garantias individuais. As políticas criminais passam, portanto, a gerenciar os conflitos sociais na lógica econômica, isto é, a utilização do sistema penal como instrumento eficiente de controle social.

Os dados apresentados acima revelaram o extraordinário salto quantitativo na população carcerária brasileira. Os investimentos em segurança pública também têm crescido nos últimos anos, especialmente na construção de estabelecimentos penais. Diante disso é possível perceber que há uma tendência de crescimento da população encarcerada no Brasil, como consequência das políticas públicas penais rigorosas que foram

\footnotetext{
2 As Casas de Correção surgiram, provavelmente, a partir de 1555, “[...] com o propósito de limpar as cidades de vagabundos e mendigos [...]”, com a criação da Bridewell, em Londres. (RUSCHE; KIRCHHEIMER, 1999, p. 61)
} 
implementadas nos últimos anos, além do significativo aumento da quantidade de pessoas submetidas ao controle do sistema penal fora dos muros da prisão.

Como se vê, as experiências de adoção de políticas de segurança pública cada vez mais segregativas não é privilégio somente dos Estados Unidos, mas também são adotadas no Brasil, portanto, é imprescindível fazer, comparativamente, as análises do contexto social e econômico dos dois países em função de que, no mesmo período, ambos os países implementaram políticas de segurança pública muito semelhantes, no sentido de, não só privatizar as penitenciárias, mas também, quando fosse o caso, permitir e incentivar a construção de estabelecimentos penais, sob o argumento da melhoria da segurança pública.

As ideias de Milton Friedman em privatizar os espaços públicos lucrativos e transformar as ações estatais adotadas em momentos de grave crise, logo, de caráter emergencial, em ações permanentes, podem ser observadas no modelo de segurança pública adotado tanto nos Estados Unidos como no Brasil, isto é, para criar a necessidade (desejo) de "segurança" e torná-la um negócio é preciso, primeiro, promover as crises da violência e da segurança pública para adotar medidas de controle social mais repressivas e, consequentemente, propor soluções, não só como a construção de presídios para resolver tais problemas, mas para servir como mecanismo de apropriação privada de ativos públicos.

Esse negócio que se tornou o sistema de segurança - público e privado - em especial o sistema prisional, é resultado dessa busca de espaços à reprodução do capital, contudo esta consequência descortina uma das questões mais controvertidas ocorridas no âmbito da segurança pública que é a aparente contradição existente entre a ideia de que a prisão se tornou, ao passar do tempo, uma instituição totalmente desacreditada, mas, em pouco tempo, inicia uma processo de encarceramento em massa e há uma verdadeira explosão da população carcerária. Nesse sentido, Wacquant (1999, p. 39) aponta que em 1967 a população carcerária nos Estados Unidos estava diminuindo, aproximadamente, 1\% ao ano, mas mesmo assim se buscava alternativas a ela, contudo, a partir da primeira metade dos anos 1970 iniciou-se um intenso processo de incremento 
ao encarceramento, resultando na explosão da população carcerária norte americana. Em sua tese de doutorado, Sandro Cabral (2006, p. 164) aponta que a taxa de aprisionamento nos Estados Unidos passa de 176 presos por 100.000 habitantes em 1975 para, 716 presos em 2005.

David Garland (2008, p. 44) afirma que "[...] as últimas três décadas testemunharam um movimento acelerado em direção oposta àquelas hipóteses que gravitaram em torno do controle do crime e da justiça criminal, na maior parte do século XX [...]", passando-se a adotar políticas criminais mais autoritárias e de combate à criminalidade, abandonando $\mathrm{o}$ que ele denominou de "previdenciarismo penal".

Para Garland (2008, p. 366-367), essa mudança no controle do crime não é uma transformação institucional, mas foram "[...] sua distribuição, seu funcionamento estratégico e sua significação social que se transformaram". De 1970 até hoje o sistema penal foi transformado radicalmente, realizando-se o "[...] maior programa de construção de penitenciárias desde a era vitoriana" (GARLAND, 2008, p. 366-367). No Brasil, o previdenciarismo penal pode ser observado, de forma incipiente, com a edição da Lei de Execução Penal de 1984, mas que foi sendo gradativamente ignorado. A partir dos anos 1990 as políticas de segurança públicas no Brasil passam a adotar orientações mais próximas daquelas prodigalizadas nos Estados Unidos e Inglaterra e enveredam para a adoção mais repressiva do controle social penal, em especial com a legislação penal e processual penal mais rígida, como se pode observar com a edição da Lei dos Crimes Hediondos, Lei Maria da Penha, Lei de Lavagem de Capitais, por exemplo, e o aumento do aparato repressivo do Estado com o aumento dos órgãos estatais de controle de crimes.

O desafio é identificar os caminhos utilizados pelo gerenciamento econômico do medo, isto é, o domínio da racionalidade econômica para enfrentar os riscos da criminalidade. Esta atuação racional da ciência econômica passa a ocorrer a partir do início dos anos de 1970 quando se dá tanto o fracasso das políticas econômicas keynesianas e do chamado Estado de bem estar social, como também se inicia o abandono do previdenciarismo penal (Garland, 2008). Do ponto de vista econômico foram criadas as circunstâncias favoráveis ao restabelecimento da hegemonia das 
finanças por meio do monetarismo, seguido pelo neoliberalismo, isto é, a partir desse abandono dos ideais de reabilitação do indivíduo e da ideia de que a criminalidade é determinada no momento das privações existenciais do indivíduo, do seu abandono pelo Estado e de seu acolhimento pelo sistema penal, seu gerenciamento deve seguir pela lógica da compatibilidade econômica, ou seja, é preciso, portanto, identificar nesta relação social os efeitos das políticas econômicas neoliberais introduzidas a partir de meados dos anos de 1970, relacionando a sobreacumulação de capital, a criação de novos espaços à acumulação de capital, o desemprego em massa, a pobreza e as privatizações, com o encarceramento de grandes massas populacionais.

Como visto, trata-se de uma análise dentro da lógica econômica, isto é, da necessidade do capital encontrar espaços próprios à sua reprodução e, neste sentido, o controle da violência mostra-se extremamente sedutor e lucrativo como novo espaço à expansão do capital. Não se pode afirmar que exista uma relação direta entre o aumento da exclusão social com o crescimento da população carcerária, entretanto, é perfeitamente possível relacionar as dinâmicas das relações de produção, influenciando a produção normativa de combate à violência, ou seja, ultrapassando a lógica do internamento e do disciplinamento para a lógica de um controle e proletarização das classes excluídas, o sistema penal dá mostras de que o controle da violência torna-se, a passos largos, um grande negócio.

Curiosamente, a realidade apresentada nos últimos 15 anos no Brasil tem proporcionado, do ponto de vista econômico, a redução das desigualdades econômicas, a diminuição da quantidade de pessoas pobres, mas, ao mesmo tempo, do ponto de vista jurídico penal, produziu uma explosão da população submetida a algum tipo de tratamento penal - dentro e fora dos muros da prisão. Essa situação torna paradoxal os discursos que apontavam a criminalidade como consequência dos problemas sociais, isto é, eles se deterioraram na medida em que o número de pessoas submetidas ao sistema prisional permanece aumentado e as desigualdades econômicas e sociais diminuindo. Apenas a título de esclarecimento, no 
Brasil, de 1970 até 2000, o índice de $\mathrm{Gini}^{3}$, considerado o melhor referencial para medir a desigualdade de renda de um país, não teve alteração, permanecendo no patamar de 0,6. A partir do ano 2000, o índice iniciou uma queda chegando, em janeiro de 2012, a 0,51.

Esta perversa relação pode ser mensurada ao analisarmos alguns dados de encarceramento. A comparação é feita com dados de encarceramento no Brasil, São Paulo e em Santa Catarina, tanto do número de encarcerados como do número de crimes patrimoniais. Esta comparação entre a população carcerária existente no Brasil, São Paulo e em Santa Catarina se explica do ponto de vista metodológico, justamente em função das diferenças estruturais entre os três entes e das semelhanças nas taxas de encarceramento, o que demonstra que a realidade do sistema de justiça criminal nacional é muito semelhante. Comparando os dados dos gráficos 1 e 2 é possível perceber tanto o aumento do encarceramento como a forte e permanente criminalização dos crimes patrimoniais, ou seja, não é uma realidade isolada de apenas um estado da federação, mas uma realidade brasileira. Ademais, esta análise permite avaliar os impactos de novas legislações e decisões judiciais que alteraram a realidade carcerária brasileira.

Tabela 1: Total de presos - Brasil, São Paulo e Santa Catarina ${ }^{4}$

\begin{tabular}{|c|c|c|c|}
\hline & Brasil & São Paulo & Santa Catarina \\
\hline $\mathbf{2 0 0 6}$ & 401.236 & 144.430 & 9.095 \\
\hline $\mathbf{2 0 0 7}$ & 422.373 & 153.056 & 10.915 \\
\hline $\mathbf{2 0 0 8}$ & 451.429 & 154.696 & 12.363 \\
\hline $\mathbf{2 0 0 9}$ & 473.626 & 163.915 & 13.340 \\
\hline $\mathbf{2 0 1 0}$ & 496.251 & 170.916 & 14.541 \\
\hline $\mathbf{2 0 1 1}$ & 513.802 & 180.059 & 14.974 \\
\hline $\mathbf{2 0 1 2}$ & 548.003 & 195.695 & 16.623 \\
\hline $\mathbf{2 0 1 4}$ & 567.655 & 204.946 & 16.366 \\
\hline
\end{tabular}

\footnotetext{
3 O índice de Gini é utilizado, normalmente, para calcular desigualdade de renda. $\mathrm{O}$ índice varia de 0 (igualdade perfeita) a 1 (desigualdade total).

4 Os dados dos anos de 2006 a 2012 foram retirados do site do Ministério da Justiça (http://portal.mj.gov.br/). Não há registro do ano de 2013, contudo o CJN divulgou pesquisa com dados mais atualizados em: < http://www.cnj.jus.br/images/imprensa/ pessoas_presas_no_brasil_final.pdf>.Acesso em: 14 out. 2014.
} 


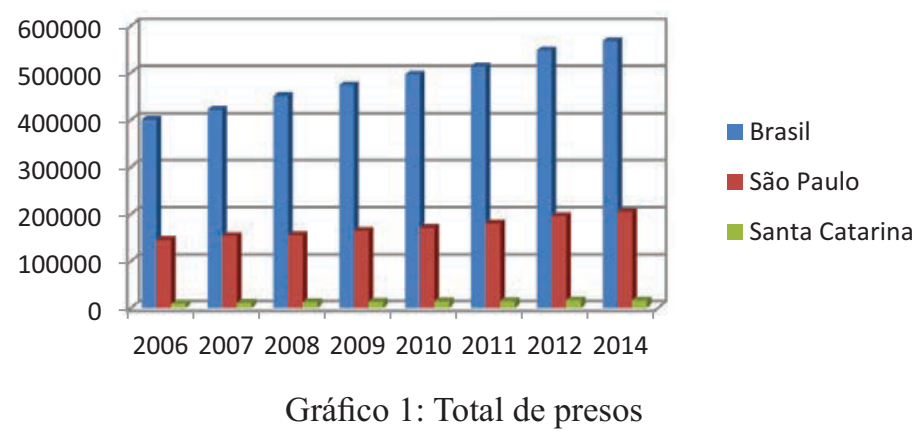

Os indicadores nos três entes mostram o crescimento da população carcerária. No Brasil, nesses oito anos, o crescimento foi de 70,68\%, em São Paulo foi de 70,47\% e, em Santa Catarina, o crescimento foi de $55,57 \%$.

É importante observar os dados da Secretaria de Segurança Pública de Santa Catarina (SSP/SC) comparando-os com aqueles divulgados pelo Ministério da Justiça (MJ) do Governo Federal, pois os dados refletem diferenças significativas. Comparando os dados informados pela SSP/SC e MJ/DEPEN percebe-se:

\begin{tabular}{|c|c|c|}
\hline Ano & Secretaria de Segurança Pública (SC) & DEPEN \\
\hline 2011 & 51.706 & 14.974 \\
\hline 2012 & 68.779 & 16.623 \\
\hline 2013 & $59.653 *$ & $17.583 * *$ \\
\hline
\end{tabular}

*População carcerária em Santa Catarina com atualização de PMSC até julho de 2013 (Fonte: $\mathrm{SSP} / \mathrm{SC}$ )

**População carcerária em Santa Catarina até junho de 2013 (Fonte: Ministério da Justiça)

Fonte: Secretaria de Segurança Pública (SC) e Ministério da Justiça (DEPEN)

Estes dados mostram que além da segregação prisional estar aumentando, a quantidade de pessoas efetivamente presas em Santa Catarina é 3 a 4 vezes maior do que aquela apresentada pelos dados do Ministério da Justiça.

Conforme o sítio eletrônico do Ministério da Justiça (http://portal. mj.gov.br/) atualmente a população carcerária brasileira gira em torno de 
mais de 574.027 pessoas presas (sem contar com as pessoas em prisão domiciliar), contudo, como se viu nos dados de Santa Catarina, este número é, tão somente, o "saldo" da quantidade de pessoas presas em junho de 2013 no Brasil, ou seja, dos remanescentes de 2012, os que entraram no sistema e os que saíram.

Pode ser feita outra análise interessante comparando o total de crimes com a quantidade de crimes patrimoniais ocorridos no Brasil, São Paulo e Santa Catarina. Neste sentido os dados apontam a seguinte quantidade de crimes:

Tabela 2: Total de Crimes patrimoniais ${ }^{5}$

\begin{tabular}{|c|c|c|c|}
\hline & Brasil & São Paulo & Santa Catarina \\
\hline $\mathbf{2 0 0 6}$ & 158.993 & 69.262 & 3.787 \\
\hline $\mathbf{2 0 0 7}$ & 208.027 & 92.539 & 5.433 \\
\hline $\mathbf{2 0 0 8}$ & 197.263 & 96.572 & 6.807 \\
\hline $\mathbf{2 0 0 9}$ & 217.762 & 103.745 & 6.416 \\
\hline $\mathbf{2 0 1 0}$ & 216.180 & 102.871 & 6.326 \\
\hline $\mathbf{2 0 1 1}$ & 240.484 & 112.942 & 7.104 \\
\hline $\mathbf{2 0 1 2}$ & 267.975 & 115.588 & 10.290 \\
\hline
\end{tabular}

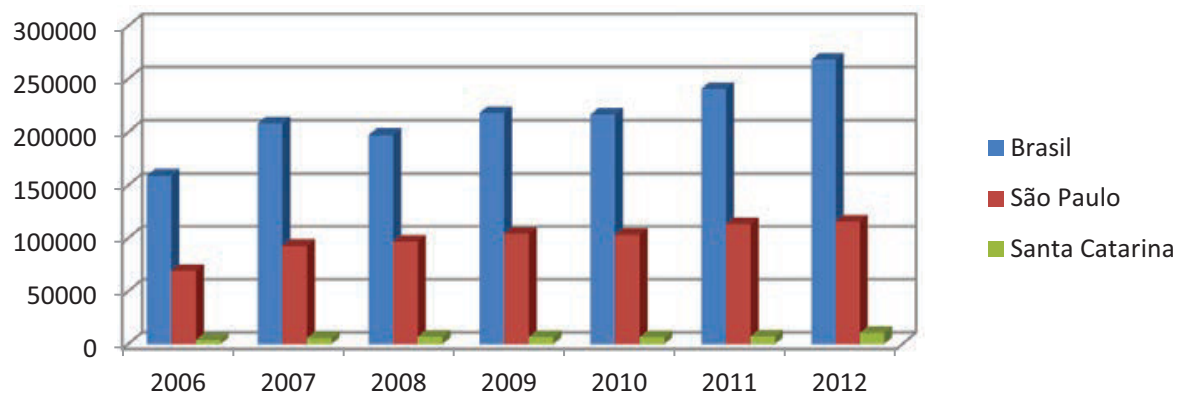

Gráfico 2: Total de Crimes patrimoniais

5 No sítio do DEPEN estão relacionados os seguintes crimes patrimoniais, todos do Código Penal, a partir de 2008: Furto Simples (art. 155); Furto Qualificado (art. 155, parágrafos 4 e 5); Roubo simples (art. 157); Roubo Qualificado (art. 157, parágrafo 2); Latrocínio (art. 157, parágrafo 3); Extorsão (art. 158); Extorsão Mediante Seqüestro (art. 159); Apropriação Indébita (art. 168); Apropriação Indébita Previdenciária (art. 168-A); Estelionato (art. 171); Receptação (art. 180); Receptação Qualificada (art. 180, parágrafo 1). 
Os dados demonstram que houve, nos anos pesquisados, um crescimento do número de crimes patrimoniais. No Brasil o crescimento foi de 59,33\%, em São Paulo foi de 59,92\% e, em Santa Catarina, foi de $32,35 \%$. É importante verificar que a seletividade dos crimes patrimoniais permanece muito semelhante no Brasil, em São Paulo e em Santa Catarina, pois esta categoria de crimes representa, em média, mais de $50 \%$ da população carcerária.

O gráfico a seguir é revelador, isso porque ao se fazer a análise das denúncias formalizadas em Santa Catarina entre os anos de 2006 e 2012, verifica-se que o foco, ao longo do tempo foi sendo alterado, contudo os crimes patrimoniais permanecem como a categoria mais criminalizada. O Gráfico 4 mostra a relação entre o total de denúncias feitas pelo Ministério Públicos de Santa Catarina e as seis categorias de crimes mais denunciados.

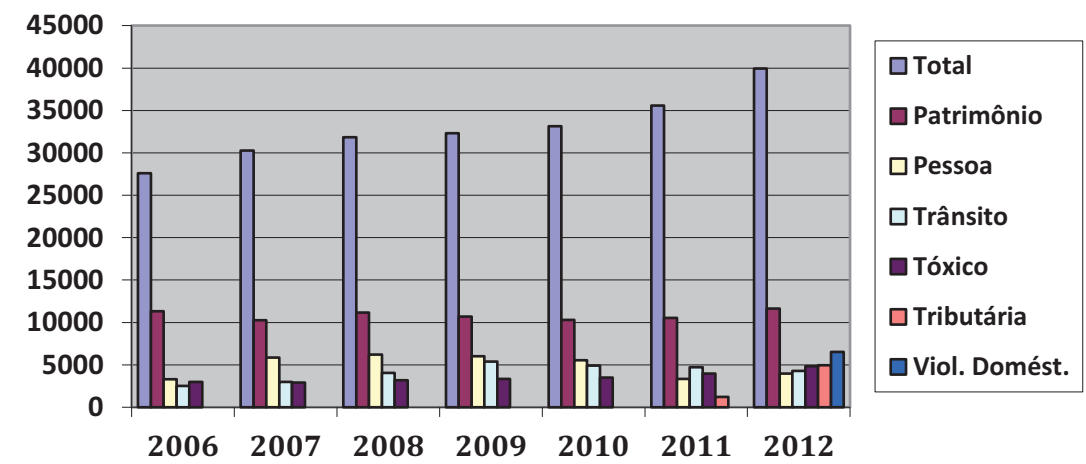

Gráfico 3 - Denúncias por categorias ${ }^{6}$

Ao mesmo tempo em que o sistema penal segue o mesmo modelo de criminalização de grandes massas populacionais, é possível perceber alteração do foco da política criminal a partir de dados colhidos em Santa Catarina. Os dados mostram uma completa alteração da política criminal catarinense, em que a persecução penal continua atingindo determinadas condutas (crimes contra o patrimônio, pessoa e tóxico), mas não mais

6 Dados retirados dos Relatórios de Gestão do Ministério Público de Santa Catarina dos anos de 2006 a 2012. 
imunizando outras como outrora (crimes de trânsito, tributários e violência doméstica).

Há um aumento de 44,61\% do número total de denúncias entre 2006 - 27.614 denúncias - e 2012 - 39.933 denúncias - sendo que os crimes contra o patrimônio aparecem como os mais denunciados nos anos pesquisados. Ao longo desses anos a situação é alterada sensivelmente chegando em 2012 com os crimes relacionados com violência doméstica e relação familiar passando a figurar como a segunda categoria mais denunciada, seguidos dos crimes contra a ordem tributária, crimes de trânsito, drogas (tóxico) e crimes contra a pessoa, entretanto os crimes patrimoniais permanecem como a categoria mais criminalizada.

Estes dados evidenciam e problematizam ainda mais a questão da justiça criminal no Brasil, isto porque, como se sabe, a situação já ultrapassou todos os limites de razoabilidade, já que a defasagem do sistema judicial e prisional para dar conta do aumento da criminalidade urbana violenta leva ao aumento do arbítrio policial e à expansão dos mecanismos informais de atuação da polícia (ADORNO, 1994), colocando em questão a própria existência de um Estado de Direito para amplos setores da população.

A atuação das instâncias judiciais penais como uma "linha de montagem" (SAPORI, 1995) se relaciona diretamente com o aumento da demanda por controle social e a crescente criminalização de condutas. Isso representa uma progressiva atuação sistemática e cada vez maior das instâncias públicas contra determinados tipos penais, bem como representa os déficits existentes no modelo tradicional de resposta à criminalidade. Com a debilitação dos controles sociais informais, o sentimento social de desordem amplia a demanda para que o poder judiciário restaure a ordem mesmo em domínios como a vizinhança e os conflitos de família ou de trânsito. Como se viu, os delitos de trânsito, a partir de 2008, receberam tratamento diferenciado no sistema de justiça criminal, figurando entre os fatos mais criminalizados.

As análises indicam esses movimentos de política criminal e mostram algumas distorções do sistema de justiça criminal como, por exemplo, o mito de que o Direito Penal deve e é aplicado indistintamente a 
todos, pois se ainda não é possível dizer sobre a atuação ideológica do Estado, é possível perceber uma atuação cada vez mais seletiva das instâncias estatais.

\subsection{A Modulação Econômica do Sistema Penal}

Os dados foram coletados para realização dessa análise comparativa, contudo esse levantamento demonstra a necessidade de entender como as novas políticas criminais estão impactando no sistema carcerário e compreender também a atuação do sistema penal neste modelo criminológico, cuja seletividade permanece indiferente, encarcerando cada vez mais pessoas e produzindo uma racionalidade vinculada à maximização de lucros.

A análise comparativa entre os indicadores demonstram os níveis de encarceramento no Brasil e permite também a percepção da modulação entre discursos e práticas econômicas e judiciais. Essa sobreposição de análise é fundamental para mensurar tanto os mecanismos de privatização do controle da violência, como as transformações das políticas criminais e sua morfologia contemporânea.

Este significativo aumento do encarceramento nas últimas décadas no Brasil está relacionado ao controle biopolítico da população, mais precisamente sobre a utilização de um sistema de controle sócio penal, como mecanismo de controle das massas, que define padrões uniformes de comportamento e a criação de desejos (normalmente um padrão de consumo) e estabelece um lugar comum de alegorias existenciais violentas, atribuindo a determinados setores sociais (comunidades e pessoas predefinidas) o crédito da barbárie contemporânea, desenvolvendo o sentimento de medo e a necessidade de se ter mais segurança, proporcionando uma consequência dramática que atinge os personagens que constituem todo o tecido social: o isolamento das pessoas.

Esse controle sócio penal possui uma eficácia produtiva, a qual foi fundamental à implantação tanto do capitalismo industrial como de sua correspondente sociedade, pois permitiu extrair dos corpos tempo e trabalho, tendo sido possível atingir tanto os ideais econômicos como os políticos, isto porque do ponto de vista econômico foi possível extrair o 
máximo de força de trabalho e, do ponto de vista político, a diminuição da capacidade de organizar uma força política apta a enfrentar as ordens do poder.

Efetivamente, é o domínio econômico e político dos corpos e, como diria Foucault (2002), é a politização do poder da vida, ou ainda, politização do poder de controlar a vida, isto porque esta nova tecnologia que se instala é dirigida à multiplicidade dos homens, não na medida em que eles se resumem em corpos, mas na medida em que ela forma uma massa global que não é individualizante, mas massificante, que se faz em direção não do homem-corpo, mas do homem-espécie, já não é uma anátomo-política do corpo humano, mas uma "biopolítica" da espécie humana, o que poderíamos chamar, hoje, diante da soberania do mercado, de uma massa de consumidores e de não consumidores.

Neste contexto, o signo da insegurança e do medo permite dar respostas cada vez mais violentas e excludentes, pois a adoção de políticas de segurança pública de combate à violência e a judicialização dos conflitos sociais estão cada vez maiores. A preocupação que surge, portanto, é sobre a possibilidade de estabelecer critérios mínimos de precaução visando à possibilidade de se admitir a governança da vida humana por meio da responsabilização de sujeitos pelos atos danosos. A resposta comumente dada é jurídica, isto é, a possibilidade de judicializar os conflitos sociais é cada vez mais comum, contudo, numa sociedade de risco na qual os danos ou os possíveis danos têm sido codificados pelo sistema de controle sócio-penal - conforme os dados apresentados acima, justamente um ramo do direito pouco translúcido e muito seletivo - são os mesmos setores da vida privada que estão sendo regulados pelo critério da mercantilização.

É compreensível que esta seja uma equação de difícil resolução, em virtude da necessidade de se estabelecer critérios suficientes para regular as possibilidades de desenvolvimento sustentável na tentativa de mitigar hipóteses de eventos danosos. As condutas futuras devem ser pautadas pela experiência necessária para seu planejamento a fim de regulamentar as ações de risco, estabelecer critérios de avaliação e de imposição 
de procedimentos para finalmente estabelecer responsabilidade por ações que efetivamente produziram danos sociais.

Historicamente, as políticas públicas adotadas com finalidade de tutelar as chamadas gerações futuras foram e seguem sendo usadas apenas no plano discursivo, entretanto, a ocorrência de eventos trágicos e devastadores, bem como seus efeitos ou apenas suas possibilidades, são utilizados como pano de fundo para se adotar as referidas políticas de segurança de viés conservador. Convém lembrar que esses eventos são empregados a fim de municiar o senso comum ${ }^{7}$ da lógica mercantil, objetivando a ocorrência do recrudescimento das leis penais e processuais penais, não obstante o fato de que sua aplicação seletiva já ocorre de forma muito mais evidente. Este é o sentido da violência e do controle social impostos pela ordem econômica, isto é, eles indicam que os vetores sociais apontam para uma guetificação racial e política nas grandes metrópoles propiciando o que Vera Malaguti Batista (2003, p. 31) chama de "adesão subjetiva à barbárie" e à necessidade de controle social.

\section{As Consequências da Interferência do Modelo Econômico na Atuação do Sistema Penal}

As profundas transformações discursivas havidas no campo das políticas criminais nos últimos 40 anos, em especial na forma como se passou a compreender o crime e o sistema penal, têm significativa vinculação com as alterações legais e institucionais relacionadas ao seu funcionamento.

\footnotetext{
7 O sentido de senso comum aqui referido, diferentemente de conhecimento científico, significa os saberes cotidianos e do senso comum de nossa sociedade com as seguintes características: a) é subjetivo, exprimindo sentimentos e opiniões individuais e de grupos; b) é qualitativo; c) heterogêneo, pois se refere a fatos que julgamos diferentes, porque os percebemos como diversos entre si; d) é individualizador, por serem qualitativos e heterogêneos; e) é generalizador, pois tendem a reunir numa só opinião ou numa só ideia coisas e fatos julgados semelhantes; f) tendem a estabelecer relações de causa e efeito entre as coisas ou entre os fatos; g) procuram projetar nas coisas ou no mundo sentimentos de angústia e de medo diante do desconhecido; h) cristalizam-se em preconceitos com os quais passamos a interpretar toda a realidade que nos cerca e todos os acontecimentos. (CHAUI, 1996, p. 174-175)
} 
Como visto nos dados de encarceramento no Brasil, as últimas décadas ficaram caracterizadas por uma crescente repressão penal e, mais ainda, em um processo de expansão do alcance do sistema penal, o qual pode ser identificado tanto na criação de leis mais rígidas (crimes hediondos, tóxicos, Lei Maria da Penha, Lavagem de Capitais) como também, de forma semelhante a países como Estados Unidos e Inglaterra, nos altos índices de encarceramento e em leis "descarceirizantes", as quais potencializam o espectro de incidência do sistema penal.

A partir das ideias trazidas por teóricos como George Rusche e Otto Kirchheimer (1999, p. 18), que demonstraram a tese de que cada sistema de produção determina as práticas do sistema penal é possível compreender a atual conjuntura política econômica relacionando-a com as políticas criminais para, em certa medida, entender a expansão do sistema penal dos pontos de vista legislativo e, principalmente, prisional. É a atuação desses sistemas intimamente relacionados que determina as concepções de justiça, mas, além disso, nos interroga sobre os impactos dessas práticas.

Todas essas mudanças podem ser entendidas como resultados de políticas de controle do crime diferenciadas e mais vinculadas às transformações econômicas e sociais dos últimos 40 anos. Toda política criminal dos anos após 1945, fundada na ideia do desajuste individual, justificava a atuação do Estado Providência e do tratamento correcional. Contudo, a transformação do pensamento criminológico a partir da década de 1970 ocorre em diversas frentes, mas é possível identificar uma grande expansão dos mecanismos institucionais de prevenção do crime e de novas estratégias de comercialização do controle dos riscos do crime.

É preciso, portanto, além de analisar o crescimento da população submetida ao sistema penal brasileiro, estabelecer a relação entre discursos econômicos e jurídicos que preponderam no momento da atuação das políticas criminais efetivadas no âmbito do poder público, produzindo, neste diapasão, a expansão da atuação do sistema penal, isto é, mais polícias, legislações mais rígidas, penas mais severas e encarceramento em massa, justamente com o propósito de identificar tanto os modos pelos quais o discurso econômico do menor custo e maior benefício se relaciona no interior da atividade criminal, como também a emergência de um 
novo modelo de justiça criminal, ou seja, se ainda há o tradicional sistema prisional com uma população em constante crescimento, há também um novo modelo de justiça criminal com regras, punições e tratamento específicos, gerando uma nova configuração do controle do crime, deixando um pouco de lado a necessidade do controle público para que as ações sejam determinadas pelos interesses privados.

O controle social no contexto da sociedade contemporânea pode ser observado a partir da sociologia e da criminologia crítica, pois essa abordagem interdisciplinar permite compreender o efeito propugnado pelo neoliberalismo em estabelecer, por meio de rigorosas políticas de segurança pública, sistemas de controle social, em detrimento de assegurar políticas públicas sociais. Os atuais mecanismos de intervenção estatal, relacionados com políticas de segurança pública, não refletem ou não significam, diretamente, melhoria na garantia dos direitos fundamentais, mas, ao contrário, atentam contra os mesmos, provocando efeitos em sentido inverso - mais violência e exclusão social.

Ademais, sabe-se que muitas vezes o aumento das taxas de criminalidade não representa diretamente um aumento da violência ou condições patológicas individuais (desvio de caráter, distúrbios psíquicos, genética) e sociais (pobreza, por exemplo), mas deve-se, entre outros fatores, ao aumento do aparato repressivo e à necessidade econômica, portanto, a necessidade de ampliação do sistema prisional (construção de estabelecimentos penais) não corresponde, diretamente, ao aumento da criminalidade, mas por um lado, ao aumento da repressão penal e, de outro, à alternativa econômica à busca de espaços à reprodução do capital.

Esses elementos estão a revelar que os discursos punitivos, especificamente de recrudescimento das políticas penais e prisionais, bem como as funções da prisão - adotada, principalmente, no modelo de recuperação pelo trabalho e disciplinamento - não estão sendo atendidos e não passam de retórica discursiva (pelo menos no sentido de recuperação pelo trabalho). Na verdade é possível relacionar os efeitos das políticas econômicas neoliberais (a sobreacumulação de capital e a criação de novos espaços à acumulação de capital, etc.) como o desemprego em massa, a pobreza e as privatizações, com o encarceramento de grandes massas populacionais. 
Observando o sistema penal e os índices de encarceramento durante os últimos 20 anos, é possível diagnosticar duas situações instigantes: a) apesar da diminuição das desigualdades econômicas, há um significativo aumento dos índices de encarceramento e a permanente seletividade da atuação do sistema penal; b) há transformações tanto na percepção e tratamento estatal do crime, como também nos modos de atuação e estruturas dos órgãos de controle e justiça criminais.

A partir de constatações empíricas é possível verificar significativas alterações nos padrões de funcionamento da Justiça Criminal, tanto em razão das mudanças legislativas, como da atuação das agências policiais e da própria máquina judiciária. São marcas das alterações do funcionamento do sistema penal: a) o abandono das práticas do previdenciarismo penal (correção) e sua transformação em um discurso de inocuidade dos criminosos e severidade da penas; b) a atuação seletiva e mais rigorosa para os crimes denominados de "colarinho branco"; c) o aumento das sanções penais (penas privativas de liberdade, pecuniárias, alternativas); d) o surgimento de leis penais e processuais penais mais rígidas (Lei de Drogas, Lei "Maria da Penha", Lei de Lavagem de Capitais, Lei Anti Terror, Lei Anti Corrupção, etc.); e) o crescimento da quantidade dos órgãos estatais de controle de crimes (COAF, Banco Central, Ministério Público, Polícias - Federal, Estadual, Rodoviária, Guardas Municipais, etc.).

É justamente a partir da década de 1970 que um conjunto de ações passa a fazer parte das políticas criminais, as quais induziram, gradualmente, ao desaparecimento do ideal de reabilitação. Esses discursos e práticas modularam a atuação do sistema penal das últimas décadas e também as transformações das políticas criminais. Dentro dos discursos criminológicos que sustentam as práticas do sistema penal, são nítidas as conexões entre o desaparecimento do ideal da reabilitação, tanto do condenado como da função da prisão, o aumento significativo da população carcerária e a atuação mais rigorosa contra os crimes econômicos, ao tempo em que, do ponto de vista econômico, houve o abandono sistemático das políticas de viés keynesiano e a adoção de práticas da acumulação flexível, como a privatização e formas de organização institucional típicas do setor privado, estabelecendo os vínculos necessários 
entre Economia e Direito, estruturando as respostas do sistema penal aos moldes da ciência econômica.

Esse comportamento patológico que embaça nossas lentes e, consequentemente, impede uma visão crítica de nossos conflitos ignora a existência do "outro", não conseguindo observar o mundo na lógica da alteridade, ou seja, não conseguimos pensar o mundo fora da lógica do consumo, pois é nesta que vivemos. Não se conseguiu, por exemplo, dividir as ruas com pedestres, ciclistas, motociclistas, pois a lógica do consumo impõe uma relação egoísta que ignora métodos alternativos de transitar pelas ruas, especialmente quando não se utiliza os métodos tradicionais. Essa intolerância está representada em diversos segmentos sociais, resultando no ódio e na incapacidade do convívio social.

A dinâmica de nossa sociedade de consumo, cuja lógica de satisfazer as necessidades está diretamente relacionada com o desejo de consumir, de comprar produtos cada vez mais novos, sem mesmo ser necessário, deve ser mensurada a partir de um paradoxo quase inconciliável: para a própria sobrevivência do modo de produção capitalista, à medida que se aumenta a capacidade produtiva, é necessário aumentar a capacidade de consumo, contudo essa equação não é tão simples quanto parece, isto porque a capacidade de consumo está diretamente condicionada com capacidade das pessoas em comprar. Na verdade poucas são as pessoas que tem esta capacidade. Não basta, por exemplo, haver pessoas suficientes com capacidade de consumir todo o alimento que se produz no mundo, é necessário, sim, que haja pessoas com capacidade de comprar alimentos. Haverá, como se sabe, excesso de alimentos e de pessoas, contudo este excesso de pessoas são, como afirma Bauman (2008), os consumidores falhos, os quais buscarão métodos alternativos de vida e, consequentemente, serão alvos do ódio dos que não toleram a diferença.

\subsection{As Conexões da Vida Contemporânea: vida virtual, isolamento e sistema penal}

Diante desse quadro, podemos pensar em, pelo menos, duas variáveis importantes: a) para o capital ser realizado com maior velocidade, necessita de consumidores, permitindo sua circulação e reprodução; b) a 
segunda situação a ser considerada é a nova condição de vida em sociedade, pois a cada dia aumentam tanto as guetificações, separações e isolamentos, como os movimentos de criminalização e de encarceramento em massa.

Conforme os dados divulgados pelo sítio eletrônico <www.e-commerce.org.br $>45,6 \%$ da população brasileira tem acesso à internet e o Brasil ocupa hoje o quinto pais com o maior número de pessoas com acesso à rede mundial. Observando os dados percebe-se que o crescimento percentual dos usuários de internet no mundo é muito grande. Os 20 países com maior número de pessoas com acesso à rede mundial possuem $76,2 \%$ do total de usuários. O crescimento de usuários no Brasil entre os anos de 2000 e 2008 foi de $284,5 \%$. No ano de 2001 havia pouco mais de 1 milhão de pessoas que faziam transações de compra e venda na internet, em 2013 esse número chegou a 51 milhões. O crescimento do volume de negócios nos últimos 10 anos é surpreendente, pois se em 2001 houve um faturamento de 0,54 bilhão de reais em 2013 o faturamento foi de 28 bilhões de reais em negócios realizados pela internet ${ }^{8}$.

É interessante observar que no Brasil esta massa de consumidores é formada, em sua maioria, por pessoas com nível de escolaridade alto, pois conforme o IBGE, os dados da PNAD de 2005 revelaram que quanto mais elevado o nível de instrução das pessoas, maior é a proporção de usuários da internet, pois enquanto $2,5 \%$ das pessoas sem instrução ou com menos de quatro anos de estudo acessaram a internet, 76,2\% da população com mais de 15 anos de estudo também o fizeram no mesmo período. Outra constatação da PNAD é que o rendimento das pessoas que não utilizaram a internet representa $1 / 3$ daquelas que acessaram.

Portanto aqui tem-se uma primeira etapa de nossa equação resolvida: como consumir mais se há menos pessoas consumindo e estamos cada vez mais dentro de nossas casas? Essa velocidade somente é encontrada na virtualidade, ou seja, nas relações de consumo de alta velocidade. Contudo, quanto mais virtual o sujeito, mais isolado do mundo, ou seja, a velocidade presente na virtualidade permite que o sujeito fique cada vez mais

8 Fonte: www.e-commerce.org.br 
estático e sozinho, produzindo um sujeito que não reconhece a existência do outro, justamente em função da virtualidade dos relacionamentos.

É necessário perceber também a forma como se banalizou a violência, bem como sua caracterização como produto de consumo, isto é, quando apresentada como objeto a ser consumido. Essas são duas outras consequências da incapacidade de perceber e reconhecer a existência da violência.

O fato de cenas de violência ser evidenciadas com recorrência causa, a cada dia, menos indignação, proporcionando, em certa medida, sua naturalização ou banalização. O bombardeio de informações sobre a violência ignora diversos fatos relevantes como: a) a expansão do sistema prisional em diversas partes do mundo; b) a perda da capacidade crítica de analisar a privatização da segurança pública (sistemas de vigilância eletrônica em locais públicos e privados, tais como nas ruas, shopping centers, casas, etc.); c) o aumento da segurança privada que são frequentemente utilizadas em bancos, estádios de futebol; d) a privatização e terceirização do sistema prisional; e) a privatização de ruas públicas que possuem guaritas e cancelas é um exemplo de situações comuns e paisagem quase obrigatória nos centros urbanos, as quais produzem uma suposta necessidade de se ter segurança.

Impressiona, ademais, a velocidade de divulgação das cenas, especialmente porque são transmitidas em tempo real e se banaliza justamente porque é normalizada, principalmente, pela forma como é colocada nas telas de televisão e computadores, o que dá a impressão de estar longe, pois virtual, não se distinguindo a realidade da virtualidade, justamente porque há uma simbiose constante entre o real e ou virtual.

É preciso, portanto, pensar a violência como técnica da obsolescência necessária, é dizer há necessidade cada vez maior de se criar elementos que produzam violência. É necessário cada vez mais consumir violência. Essa mesma violência garante, de um lado, a sensação de medo necessária para permitir e legitimar a atuação mais rigorosa dos instrumentos repressivos do Estado e, de outro, conduzir os cidadãos a, progressivamente, virtualizarem seus relacionamentos (profissionais e afetivos), proporcionando, em grande medida, o isolamento e a solidão. Essa 
é a contemporânea subjetividade que se caracteriza pela produção permanente e uniforme dos desejos de segurança e intolerância, a qual está a fomentar uma cruel rotina de nosso cotidiano: o isolamento.

Surge, então, o paradoxo entre racionalidades: se, por um lado, pretende-se um mundo melhor e mais digno, por outro encontramos a barbárie das guerras, da exploração do trabalho infantil, da exploração sexual, a precarização à relação e aos direitos trabalhistas, o "falecimento" do estado de bem estar social, a exploração dos países de primeiro mundo em relação aos países subdesenvolvidos, etc., surgindo com mais intensidade um estado policial e não mais social.

O mercado, como o lugar da produção normativa e da decisão política, impõe o consumo de segurança e a "metáfora" da guerra permite imaginar a violência em proporções muito difusas, a ponto de, em muitos momentos, adquirir personalidade, constituindo-se em sujeito nas relações sociais. É fácil, por exemplo, ouvir expressões como "a violência chegou à cidade" ou "a violência no trânsito mata mais um", permitindo a total despersonalização e não responsabilização do sujeito. Aqui reside o sentido que a violência proporciona, pois se de certa forma existe a produção de uma violência e ela é despersonalizada, não há responsáveis, exceto nos casos em que a violência é praticada por "pessoas comuns" e o sistema penal as encontra. É possível dizer que a personalidade da violência pode ser determinada pelo próprio sistema penal, iniciando pela polícia, para em seguida personalizar-se com o delinquente.

Assim, no mesmo instante em que a violência é despersonalizada, discursos são criados e divulgados exatamente no sentido de permitir que ela esteja em toda parte, tornando-se, portanto, um sujeito: "a violência". É esta "violência" a responsável pelos danos ocasionados no trânsito, entretanto, o protagonista da alta criminalidade é um indivíduo com nome, morador da favela ou em bairros pobres da cidade. A forma estatal de responder aos casos de violência toma sentidos diferentes: no primeiro caso, o sentido aponta às políticas públicas de segurança como as campanhas de educação no trânsito, e no segundo caso o vetor aponta às políticas de segurança públicas tais como o recrudescimento do sistema penal por 
meio de leis penais mais severas e o controle sócio penal. Dessa forma, a estrutura da sociedade aponta, seletivamente, para sentidos diferentes.

Assim é que o sentido da violência toma rumos e respostas distintas, evitando-se, com isso, a não incidência do sistema penal para todos, mas tão somente ao necessário para manutenção do próprio sistema. Não obstante o diagnóstico do aumento da violência, dos altos índices de criminalidade, do desconforto apresentado pela sensação de insegurança e o consequente medo estabelecido, o sistema penal continua atuando de forma seletiva, sendo visível a incapacidade dos sistemas em permitir a implementação de políticas públicas de segurança.

\section{Conclusão}

É possível, portanto, contextualizar nossa vivência imaginando esse cenário que ultrapassa toda atuação do Estado até aqui delineada, isso porque é o mercado, como "ágora" da produção normativa e da decisão política, que permite a existência de todas essas violações e sua manifestação somente se dará no momento preciso de enfrentamento, isto é, toda atuação violenta poderá ocorrer, por mais rigorosa que possa parecer, e somente se dará no sistema de justiça quando: a) não interferir na ordem econômica; b) representar, no máximo, a destruição parcial do capital, mas não suficientemente para sua destruição total; e, por fim, c) a decisão judicial não ameaçar o modo de produção, pois diante conflito de interesses entre desenvolvimento econômico e violação de direitos a tendência é que este pereça.

Essa violência, ao legitimar a atuação mais rigorosa dos instrumentos repressivos do Estado, expõe outro pressuposto com reflexos perturbadores, pois permite ao cidadão, em seu imaginário, a visão do Estado protetor, que disponibiliza, simbolicamente, a segurança pública. Atentese, pois essa segurança somente será possível no âmbito domiciliar, nos espaços privados, onde seus direitos estarão preservados, tanto aqueles relacionados à segurança quanto os direitos do consumidor, ou seja, a tutela pública do Estado em relação à preservação de direitos do cidadão somente será possível no espaço privado, pois, longe da rua haverá a sen- 
sação de segurança. É aqui que este novo paradigma se realiza e encontra um novo sentido, pois é no espaço virtual, sem a possibilidade da violência dos órgãos repressores e no isolamento do indivíduo, que se cria, paradoxalmente, a massa de consumidores.

Todo esse palco encenado favorece o isolamento do cidadão: perde a política, ganha o mercado. Perde a política, pois não há mais o indivíduo (in= não, divi=divisível, duo=dois, não divisível por dois) e deixa de existir o sentimento de agregação, o sentimento de pertencimento a um grupo. Aparece uma legião de abandonados (sem bando), apenas seres isolados. Em grande medida, o isolamento e a solidão acarretam a destruição das agregações e da formação política dos grupos. Ganha o mercado, pois, a despeito do desaparecimento do indivíduo, surge a massa, uma verdadeira colônia de vários grupos unidos pela homogeneidade de desejos: os consumidores.

Esse elemento isolado, antes sujeito de desejos, é refém das práticas indutivas ou dos sujeitos de desejos induzidos. O paradigma se sustenta para favorecer não mais segurança pública, mas tão somente segurança nos negócios. É cidadão, portanto, aquele que tem preservado seus direitos de consumidor e o Estado tem a atribuição de disponibilizar este tipo de segurança. Este mesmo cidadão torna virtuais seus relacionamentos, destituindo o homem político, fomentando o homem virtual.

Por fim, é necessário refletir sobre a aparente liberdade que sonega informações, pois as estratégias de poder, especialmente aquela efetivada pelo sistema penal, observa e induz a determinadas práticas, potencializando o deslocamento da soberania do Estado para o mercado, tendem a implementar rigorosas políticas de segurança pública de perfil cada vez mais autoritário, tipicamente de "combate" e de "exclusão", privatizando o controle social e explorando economicamente a violência.

\section{Referências}

ADORNO, Sérgio. Violência, controle Social e cidadania. Dilemas da Administração da Justiça Criminal no Brasil. Revista Crítica de Ciências Sociais, Coimbra, n. 41, p. 101-127, dezembro, 1994. 
BAUMAN, Zygmunt. Vida para consumo: a transformação das pessoas em mercadorias. Tradução de Carlos Alberto Medeiros. Rio de Janeiro: Jorge Zahar, 2008.

CABRAL, Sandro. Além das grades: uma análise comparada das modalidades de gestão do sistema prisional. Doutorado, Universidade Federal da Bahia, Salvador, 2006

CHAUI, Marilena. Convite à filosofia. 7. ed. São Paulo: Ática, 1996. CHESNAIS, François. A mundialização do capital. Tradução de Silvana Finzi Foá. São Paulo: Xamã, 1996. 335 p.

E-COMMERCE [2014]. Disponível em: <www.e-commerce.org.br>. Acesso em: 25 maio 2014.

FOUCAULT, Michel. Vigiar e punir: história da violência nas prisões. 14. ed. Petrópolis: Vozes, 1996, 277 p.

. Em defesa da sociedade: curso do Collège de France (19751976). Tradução de Maria Emantina Galvão. São Paulo: Martins Fontes, 2002. 382 p.

GARLAND, David. A cultura do controle: crime e ordem social na sociedade contemporânea. Tradução de André Nascimento. Rio de Janeiro: Revan, 2008. 440 p.

IBGE - Instituto Brasileiro de Estatística e Geografia. [2014]. Disponível em: 25 maio 2014.

RUSCHE, Georg; KIRCHHERIMER, Otto. Punição e estrutura social. Coleção Pensamiento Criminológico n. 3. Tradução, revisão técnica e nota introdutória de Gizlene Neder. Rio de Janeiro: Freitas Bastos, 1999. $274 \mathrm{p}$.

HARVEY, David. Espaços de esperança. Tradução de Adail Ubirajara Sobral e de Maria Stela Gonçalves. São Paulo: Loyola, 2004. 382 p.

LUXEMBURGO, Rosa. A acumulação do capital. São Paulo: Abril, 1984. (v. II)

MALAGUTI BATISTA, Vera. Difíceis ganhos fáceis: drogas e juventude pobre no Rio de Janeiro. 2. ed., Rio de Janeiro: Revan. 2003, p. 31. 
MÉSZÁROS, István. Para além do capital. Rumo a uma teoria da transição. Tradução de Paulo César Castanheira e Sérgio Lessa. São Paulo: Boitempo e UNICAMP, 2002. 1.102 p.

MINISTÉRIO da Justiça. [2014]. Disponível em: <http://portal.mj.gov. br/data/Pages/MJA21B014BPTBRIE.htm>. Acesso em: 25 maio 2014.

MINISTÉRIO Público do Estado de Santa Catarina. [2014]. Disponível em: <www.mp.sc.gov.br>. Acesso em: 25 maio 2014.

POLANYI, Karl. A grande transformação: as origens da nossa época. Tradução de Fanny Wrobel. 7. ed. Rio de Janeiro: Campus, 2000. 349 p.

SAPORI, Luís Flávio. A Administração da justiça criminal numa área metropolitana. Revista Brasileira de Ciências Sociais, São Paulo, n. 29, p. 143-158, outubro, 1995.

SECRETARIA de Segurança Pública do Estado de Santa Catarina. [2014]. Disponível em: www.ssp.sc.gov.br>. Acesso em: 25 maio 2014. WACQUANT, Loïc. Crime e castigo nos Estados Unidos: de Nixon a Clinton. Revista de Sociologia e Política, UFPR, Curitiba, n. 13, p. 3950, nov. 1999.

Sergio Francisco Carlos Graziano Sobrinho é Doutor em Direito pela Pontifícia Universidade Católica do Rio de Janeiro, Mestre em Direito pela Universidade Federal de Santa Catarina, e atualmente realiza estágio de pós doutorado no Programa de Pós Graduação em Ciências Criminais da Pontifícia Universidade Católica do Rio Grande do Sul, com bolsa do PNPD/CAPES.

E-mail: sergiograziano@gmail.com

Endereço profissional: Pontíficia Universidade Católica do Rio Grande do Sul. Av. Ipiranga, 6681, Paternon, Porto Alegre, RS, Brasil. 